\title{
Psycho-trauma, psychosocial adjustment, and symptomatic post-traumatic stress disorder among internally displaced persons in Kaduna, Northwestern Nigeria
}

\author{
Taiwo Lateef Sheikh ${ }^{1,2 *}$, Abdulaziz Mohammed ${ }^{1}$, Samuel Agunbiade ${ }^{1}$, Joseph lke $^{1}$, William N. Ebiti ${ }^{1}$ and \\ Oluwatosin Adekeye ${ }^{2}$
}

' Clinical Services, Federal Neuropsychiatric Hospital, Kaduna, Nigeria

${ }^{2}$ Department of Psychiatry, Ahmadu Bello University, Zaria, Nigeria

\section{Edited by:}

Michael Noll-Hussong, University of

Ulm, Germany

\section{Reviewed by:}

Tariq Munshi, Queen's University,

Canada

Casimiro Cabrera Abreu, Queen's

University, Canada

Michael Noll-Hussong, University of

Ulm, Germany

*Correspondence:

Taiwo Lateef Sheikh, Clinical Services, Federal Neuropsychiatric Hospital,

Aliyu Makama Road, P. M. B. 2187,

Barnawa, Kaduna 800001, Nigeria

e-mail: latshe@yahoo.com

Background: In April 2011, a post election violent conflict in Northern Nigeria led to resettlement of internally displaced persons (IDPs) in a camp in Kaduna, the worst affected state. We set out to determine prevalence and socio-demographic factors associated with posttraumatic stress disorder (PTSD) among IDPs. We also determined types of psycho-trauma experienced by the IDPs and their psychosocial adjustment.

Methods: Cross-sectional systematic random sampling was used to select 258 adults IDPs. We used Harvard trauma questionnaire to diagnose "symptomatic PTSD," composite international diagnostic interview (CIDI) for diagnosis of depression, and communal trauma event inventory to determine exposure to psycho-trauma. We assessed social adjustment using social provision scale. Multiple logistic regression analysis was used to determine independent predictors of PTSD.

Results: Of the 258 IDPs, 109 (42.2\%) had a diagnosis of PTSD, 204 (79.1\%) had poor living conditions, and only $12(4.7 \%)$ had poor social provision. The most frequent psychotraumas were destruction of personal property $(96.1 \%)$, been evacuated from their town $(96 \%)$ and witnessing violence (88\%). More than half $(58 \%)$ of IDPs had experienced $11-$ 15 of the 19 traumatic events. Independent predictors of PTSD among respondents were having a CIDI diagnosis of depression (adjusted odds ratios 3.5, 95\% confidence interval $1.7-7.5 ; p=0.001)$ and witnessing death of a family member $(3.7,1.2-11.5 ; p=0.0259)$.

Conclusion: We concluded that exposure to psycho-trauma among IDPs in Kaduna led to post conflict PTSD. Death of a family member and co-morbid depression were independent predictors of PTSD among IDPs. Though their living condition was poor, the IDPs had good psychosocial adjustment. We recommended a structured psychosocial intervention among the IDP targeted at improving living condition and dealing with the psychological consequences of psycho-trauma.

Keywords: post traumatic stress disorder, internally displaced persons, psychosocial adjustment, depression, psycho-trauma

\section{INTRODUCTION}

In April 2011 , a post election violent conflict in Northern Nigeria killed 800 and displaced 65,000 people over a period of 3 days (1). The majority of the fatalities $(88 \%)$ were from Kaduna state of Nigeria, known for ethno-religious conflicts. A camp for the internally displaced persons (IDPs) was set up in Kaduna city, the capital of the state to cater for the medical and social needs of the IDPs. Despite the increase in communal conflicts in Northern Nigeria after the country returned to democratic rule in 1999 (2), only few studies had been conducted on possible development of post-traumatic stress disorder (PTSD) among the survivors of the violent conflicts. Obilom and Thacher (3) studied PTSD following ethno-religious conflict in Jos, a neighboring state to Kaduna. He found "witnessing or been victims of personal attacks," 'losing possessions," and "burning of homes" as the leading psycho-trauma among the study population.

We set out to determine the prevalence of PTSD, and types of psycho-trauma experienced by the IDPs and their psychosocial adjustment. We also determined factors associated with PTSD.

\section{MATERIALS AND METHODS STUDY SETTING}

The study was conducted in Kaduna city, the capital of Kaduna state located in the Northwestern zone of Nigeria in March 2013. The IDP camp was located on the outskirt of the city in a transit camp originally built for Hajj pilgrims (Muslims traveling to Saudi 
Arabia for the holy pilgrimage). Over 2,500 IDPs were settled in the camp.

\section{STUDY DESIGN}

We conducted a cross-sectional study among male and female IDPs aged $\geq 18$ years. We defined IDPs as people living within the camp, who have been displaced from their original communities as a result of the violent conflict following the April 2011 elections in Nigeria. We excluded persons already diagnosed with a mental disorder prior to the post election conflict and those who refused consent.

\section{SAMPLE SIZE DETERMINATION}

A minimum sample size of 230 was calculated using the Leslie and Kish (4) formula for estimating sample size for cross-sectional study.

$$
n=\frac{\left(Z \alpha^{2} p q\right)}{d^{2}}
$$

where $n=$ minimum sample size; $Z \alpha$ set at $5 \%$ significant level $=1.96 ; p=$ estimate of prevalence of arousal symptoms of PTSD among the IDPs in a similar study in Nigeria $=84 \%=0.84$ (3); $d=$ level of precision $(5 \%) ; q=1-p$.

$$
\begin{aligned}
& n=\frac{\left(1.96^{2} \times 0.84 \times 0.16\right)}{0.05^{2}} \\
& n=206
\end{aligned}
$$

Adjusting for non-response rate of $10 \%$

$$
=\frac{n r}{(r-1)}
$$

where $n=$ calculated sample size and $r=10$

$$
\begin{aligned}
& =\frac{206 \times 10}{10-1} \\
& =228
\end{aligned}
$$

minimum sample size $=228$.

For the study, we sampled 258 IDPs.

\section{SAMPLING TECHNIQUE}

We used systematic sampling technique to select the respondents for the study. A sampling frame was created from the line list of all the IDPs obtained from the welfare committee of the camp. We excluded IDPs who were $<18$ years of age. Of the 2,500 IDPs, 1,502 were included in the final sampling frame for the study. We divided the sampling frame by the study sample size to determine the sampling interval. The first IDP was selected from the sampling frame using a table of random numbers, and then using the sampling interval we selected subsequent respondents until the required sample size was achieved.

\section{STUDY INSTRUMENT}

We designed a questionnaire to measure the socio-demographic characteristics of IDPs and their living conditions, which was assessed by asking the following questions: availability of sleeping mat, private facility, toilets or latrine, sufficient food, and protection from animals and insects for individual IDPs. We also asked if the accommodations were cramped, if their health was good, and if they had enough organizational support. Conflict-related trauma was assessed with a shortened version of the communal traumatic events inventory used to study Bosnian refugees (5). We included only trauma events, the IDPs were likely to have experienced and respondents were to indicate "yes" or "no" depending on experience during the conflict. To measure the IDPs psychosocial adjustment, we adapted the social provision scale originally developed by Cutrona and Russell (6). Twelve of the 24 questions that captured the components of reassurance of worth, reliable alliance, and guidance were used for the study. We defined good psychosocial adjustment as answering "strongly agree" or "agree" to 8 of the 12 questions. We used the composite international diagnostic interview (CIDI) to generate diagnosis of depression among the respondents. CIDI is a highly structured clinical interview instrument derived from the National Institute of Mental Health (NIMH) diagnostic interview schedule (DIS) and the present state examination (PSE). The instrument has been proven to have cross-cultural validity (7) and the Hausa version was used in a community survey in Nigeria (8). Finally, we used the Harvard trauma questionnaire (HTQ) (9) designed by Harvard Program in Refugee Trauma, Massachusetts General Hospital for the diagnosis of symptomatic PTSD. The PTSD section consists of 16 questions based on the diagnostic criteria of the diagnostic and statistical manual for mental disorders fourth edition (DSM IV) (10). The questions were measured on a 5 -point severity scale of $1-5$. Scores for each respondent were summed up and divided by the number of items (16) to derive the score for each individual. Individuals with total score $>2.5$ were considered symptomatic for PTSD (9). The cut off score of 2.5 had been standardized for several version of HTQ (11-13) and the HTQ had been validated for use in displaced persons in several cross-cultural studies (14-16). The questionnaire was translated to Hausa the main language spoken in Northern Nigeria and back translated to English. The translation underwent detailed review by the study team and followed recommended guidelines $(9,17)$.

\section{DATA COLLECTION AND PROCEDURE}

We recruited six data collectors who could speak both English and Hausa language fluently and were experienced in data collection from prior activities. They were trained for a period of 5 days on the use of the study questionnaire and interview techniques prior to the commencement of the study. Data collection took place over a period of 6 days and the average duration of each interview was $40 \mathrm{~min}$. Five supervisors made up of psychiatrists and senior resident doctors supervised the data collectors.

\section{DATA ENTRY AND ANALYSIS}

Data were entered into Epi info 3.3.2, cleaned, and edited for inconsistencies before analysis. Descriptive statistics were used in summarizing the data, while analytical statistics were used to test 
Table 1 | Socio-demographic characteristics of IDPs ${ }^{a}$ by gender of respondents $(n=258)$

\begin{tabular}{|c|c|c|}
\hline Characteristics & $N$ & $(\%)$ \\
\hline \multicolumn{3}{|l|}{ Sex } \\
\hline Female & 134 & (51.9) \\
\hline \multicolumn{3}{|l|}{ Religion } \\
\hline Islam & 258 & $(100)$ \\
\hline \multicolumn{3}{|l|}{ Marital status } \\
\hline Married & 154 & (59.7) \\
\hline Widowed & 53 & (20.5) \\
\hline Single & 35 & (13.6) \\
\hline Divorced & 11 & (4.3) \\
\hline Separate & 5 & (1.9) \\
\hline \multicolumn{3}{|c|}{ Level of education ${ }^{b}$} \\
\hline Quranic & 101 & (39.3) \\
\hline Primary & 68 & (26.5) \\
\hline Secondary & 50 & (19.5) \\
\hline None & 31 & (12.1) \\
\hline Tertiary & 7 & $(2.7)$ \\
\hline \multicolumn{3}{|c|}{ Employment status } \\
\hline Unemployed & 176 & $(68.2)$ \\
\hline Employed & 65 & $(25.2)$ \\
\hline Student & 2 & (0.8) \\
\hline Retired & 3 & $(1.2)$ \\
\hline
\end{tabular}

${ }^{a} I D P S$, internally displaced persons.

${ }^{b} n=257$.

for significant associations and predictors. We used frequencies, proportions, and tables to summarize our data, bivariate analysis and multiple logistic regressions were performed to identify factors associated with the occurrence of symptomatic PTSD. We dichotomized the outcome of HTQ based on a cut off score of 2.5 into those with PTSD and those without PTSD. The chi square test was used in determining statistically significant associations, while factors with $p$ values $<0.05$ were included in the logistic regression model. Adjusted odds ratios (AORs) were determined with $95 \%$ confidence interval $(\mathrm{CI})$ to identify predictors of PTSD.

\section{ETHICAL CONSIDERATION}

Ethical approval was granted by the health research ethical committee of the Federal Neuro-Psychiatric Hospital Kaduna before onset of the study. Participating IDPs were required to give an informed consent before inclusion in the study. All potential subjects were presented with a consent form, which described the type of study being done, the purpose of the study, and the subject's rights as a participant in the study, including the right to confidentiality and the right to withdraw from the study. Names were not included in any of the findings and no financial inducement was given to any respondent. Two psychiatrists, four psychiatric nurses, a clinical psychologist, and a pharmacist provided medical advice if needed and at the end of the study those determined to have significant distress were referred to a specialist psychiatric hospital for management.
Table 2 | Exposure of IDPs ${ }^{a}$ to traumatic events $(N=258)$.

\begin{tabular}{|c|c|c|c|}
\hline \multirow[t]{2}{*}{ Events } & \multicolumn{3}{|c|}{$\begin{array}{l}\text { Number of persons } \\
\text { experiencing event }\end{array}$} \\
\hline & Number & $\%$ & $95 \% \mathrm{Cl}^{\mathrm{b}}$ \\
\hline \multicolumn{4}{|l|}{ Type of trauma event experienced } \\
\hline Destruction of personal property ${ }^{c}$ & 247 & 96.1 & $93.1-98.1$ \\
\hline Evacuated from town & 247 & 95.7 & $92.5-97.9$ \\
\hline Lost property ${ }^{b}$ & 246 & 95.7 & $92.5-97.8$ \\
\hline Separated from loved ones & 239 & 92.6 & $88.7-95.5$ \\
\hline Witness violence & 227 & 88.0 & $83.4-91.7$ \\
\hline Death of family member & 224 & 86.8 & $82.1-90.7$ \\
\hline III health ${ }^{b}$ & 215 & 83.7 & $78.6-88.0$ \\
\hline Family beaten & 180 & 69.8 & $63.8-75.3$ \\
\hline Witness torture ${ }^{b}$ & 177 & 68.9 & $62.8-74.5$ \\
\hline Witness death of family member ${ }^{b}$ & 175 & 68.1 & $62.0-73.7$ \\
\hline Without shelter ${ }^{\mathrm{b}}$ & 165 & 64.2 & $58.0-70.1$ \\
\hline Stolen possession ${ }^{b}$ & 154 & 59.9 & $53.7-66.0$ \\
\hline Shortage of clothing ${ }^{b}$ & 150 & 58.4 & $52.1-64.5$ \\
\hline Shortage of medicine ${ }^{b}$ & 149 & 58.0 & $51.7-64.1$ \\
\hline Physical injury & 118 & 45.7 & $39.5-52.0$ \\
\hline Beaten & 101 & 39.1 & $33.2-45.4$ \\
\hline Lack of food & 100 & 38.8 & $32.8-45.0$ \\
\hline Loved ones disappear & 86 & 33.3 & 27.6-39.4 \\
\hline Rape or sexual molestation ${ }^{d}$ & 4 & 1.7 & $0.5-4.2$ \\
\hline \multicolumn{4}{|c|}{ Cumulative trauma events experienced } \\
\hline $0-5$ & 4 & 1.6 & $0.4-3.9$ \\
\hline $6-10$ & 57 & 22.1 & $17.2-27.7$ \\
\hline $11-15$ & 149 & 57.8 & $51.5-63.9$ \\
\hline$\geq 16$ & 48 & 18.6 & $14.0-23.9$ \\
\hline
\end{tabular}

a IDPS, internally displaced persons.

${ }^{b} \mathrm{Cl}$, confidence interval.

${ }^{c} n=257$.

${ }^{d} n=240$.

\section{RESULTS}

A total of 258 interviews were conducted. The mean age of the IDPs was 38.7 years (SD: 15.2 years) with a range of 18-95 years. Of the 258 IDPs, 134 (51.9\%) were females, all (100\%) practiced Islam, $53(20.5 \%)$ were widowed and $68.2 \%$ were unemployed (Table 1).

Of the 258 respondents, 109 (42\%) of them had a diagnosis of PTSD.

The most trauma event experienced by the IDPs (Table 2) were destruction of personal property $(96.1 \%)$ and been evacuated from their town $(96 \%)$. More than three-quarter had witnessed violence $(88 \%)$, reported the death of a family member $(87 \%)$, and suffered ill health (84\%). More than two-thirds had witnessed torture $(69 \%)$ and witnessed death of family member (68\%). Only four (1.7) IDPs reported rape or sexual molestation. More than half $(58 \%)$ of the IDPs had experienced $11-15$ of the 19 traumatic events covered by the questionnaire.

The exposure of female and male IDPs to 9 of the 19 traumatic events showed significant variations (Table 3). Of the IDPs that 
Table 3 | Types of trauma event experienced by IDPa by gender.

Events

Type of trauma event experienced

Beaten

Witness death of family member

Physical injury

Witness torture

Lack of food

Loved ones disappear

Stolen possession

Without shelter

III health

Lost property

Evacuated from town

Family beaten

Destruction of personal property

Shortage of clothing

Witness violence

Shortage of medicine

Separated from loved ones

Death of family member

Rape or sexual molestation
Number of persons experiencing event

\begin{tabular}{|c|c|c|c|c|c|}
\hline \multicolumn{2}{|c|}{ Female } & \multicolumn{2}{|c|}{ Male } & \multirow[t]{2}{*}{$\mathrm{OR}^{\mathrm{b}}\left(95 \% \mathrm{Cl}^{\mathrm{c}}\right)$} & \multirow[t]{2}{*}{$p$ Value } \\
\hline$n$ & $\%$ & $n$ & $\%$ & & \\
\hline 27 & 26.7 & 74 & 73.3 & $0.2(0.1-0.3)$ & $<0.000$ \\
\hline 76 & 43.4 & 99 & 56.6 & $0.3(0.2-0.6)$ & $<0.000$ \\
\hline 44 & 37.3 & 74 & 62.7 & $0.3(0.2-0.6)$ & $<0.000$ \\
\hline 79 & 44.6 & 98 & 55.4 & $0.4(0.2-0.7)$ & $<0.001$ \\
\hline 39 & 39.0 & 61 & 61.0 & $0.4(0.3-0.7)$ & $<0.001$ \\
\hline 32 & 37.2 & 54 & 62.8 & $0.4(0.2-0.7)$ & $<0.001$ \\
\hline 68 & 44.2 & 86 & 55.8 & $0.5(0.3-0.8)$ & 0.003 \\
\hline 79 & 47.9 & 86 & 52.1 & $0.6(0.4-1.1)$ & 0.01 \\
\hline 118 & 54.9 & 97 & 45.1 & $2.0(1.0-4.0)$ & 0.05 \\
\hline 131 & 53.3 & 115 & 46.7 & $3.0(0.8-11.7)$ & 0.09 \\
\hline 124 & 51.0 & 121 & 49.0 & $0.4(0.1-1.5)$ & 0.2 \\
\hline 89 & 49.4 & 91 & 50.6 & $0.7(0.4-1.2)$ & 0.2 \\
\hline 127 & 51.4 & 120 & 48.6 & $0.5(0.1-1.8)$ & 0.3 \\
\hline 74 & 49.3 & 76 & 50.7 & $0.8(0.5-1.3)$ & 0.4 \\
\hline 116 & 51.1 & 111 & 48.9 & $0.8(0.4-1.6)$ & 0.5 \\
\hline 79 & 53.0 & 70 & 47.0 & $1.1(0.7-1.9)$ & 0.6 \\
\hline 125 & 52.3 & 114 & 47.7 & $1.2(0.5-3.1)$ & 0.7 \\
\hline 117 & 52.2 & 107 & 47.8 & $1.1(0.5-2.2)$ & 0.8 \\
\hline 2 & 50.0 & 2 & 50.0 & $0.8(0.1-5.7)$ & 0.8 \\
\hline
\end{tabular}

${ }^{a}$ IDPs, internally displaced persons.

${ }^{b} \mathrm{OR}$, odds ratio.

${ }^{c} \mathrm{Cl}$, confidence interval.

were beaten, only $27 \%$ were females [odd ratio (OR) $0.2,95 \% \mathrm{CI}$ $0.1-0.3 ; p<0.000]$. Among IDPs witnessing death, less than half $(43 \%)$ were females $(0.3, \mathrm{CI}, 0.2-0.6 ; p<0.000)$ and only $37 \%$ of females had physical injury $(0.3,0.2-0.6 ; p<0.000)$. Among IDPs that had witnessed torture, $45 \%$ were females $(0.4,0.2-0.7$; $p<0.001)$. Other traumatic events that showed significantly less exposure to females were lack of food $(0.4,0.3-0.7 ; p<0.001)$, disappearance of loved ones $(0.4,0.2-0.7 ; p<0.001)$, having personal belongings been stolen $(0.5,0.3-0.8 ; p=0.003)$, and being without shelter $(0.6,0.4-1.1 ; p=0.01)$. The only psycho-trauma with more females been exposed (54.5\%) was ill health $(2.0,1.0-4.0$; $p=0.05)$.

Of the 258 IDPs, 109 (42.2\%) had a diagnosis of PTSD, 204 (79.1\%) had poor living conditions, but only $12(4.7 \%)$ had poor social provision.

At bivariate analysis 6 of the 19 trauma events covered by this study were significantly associated with a diagnosis of symptomatic PTSD (Table 4). IDPs who had PTSD were 5 times more likely to have witnessed death of a family member (5.03, 1.913.5 ; $p<0.00$ ), 3 times more likely to have been exposed to $\geq 16$ trauma events $(2.8,1.5-5.3 ; p<0.00)$, and twice more likely to have had their personal belonging stolen $(2.0,1.2-3.4 ; p<0.01)$. Furthermore, IDPs with a diagnosis of PTSD were four times more likely to have a co-morbid diagnosis of depression (3.8, $1.9-7.7 ; p<0.00)$. There were no socio-demographic associations of PTSD.
We performed multiple logistic regression analysis on all the eight factors that were significantly associated with PTSD at bivariate analysis (Table 5). Of the eight factors, having a CIDI diagnosis of depression (AOR 3.5, 1.7-7.5; $p<0.001$ ) and experiencing death of a family member $(3.7,1.2-11.5)$ remained as independent predictors of PTSD among the IDPs.

\section{DISCUSSION}

In this study, destruction of personal property, being evacuated from town, witnessing violence, reported death of a family member, and suffering ill health were the most frequent psychotrauma experienced by the IDPs. The violent nature of the conflict was demonstrated by more than half of the IDPs experiencing 11-15 psycho-traumatic events during the conflict. The level of exposure of IDPs to psycho-traumatic events such as witnessing death of a relative, possessions being stolen, and witnessing violence were much higher among this IDPs compared to a similar study done in Northern Nigeria (3). Rape and sexual molestation violence appeared not to have been widely used in this conflict. The prevalence of rape and sexual molestation was similar to that reported in a study in Bosnia (18), but it is much lower than that reported in a study of IDPs in Northern Uganda (16). We found females to be significantly less exposed to psycho-trauma, which is consistent with the findings of higher exposure of men to psycho-trauma during conflicts reported in Northern Uganda. Due to the less exposure of females to 
Table 4 | Factors associated with PTSDa among IDPs.

\begin{tabular}{|c|c|c|c|c|c|c|}
\hline \multirow[t]{2}{*}{ Characteristics } & \multicolumn{2}{|c|}{ PTSD } & \multicolumn{2}{|c|}{ No PTSD } & \multirow[t]{2}{*}{$\mathrm{OR}^{\mathrm{b}}\left(95 \% \mathrm{Cl}^{\mathrm{c}}\right)$} & \multirow[t]{2}{*}{$p$ Value } \\
\hline & $n$ & $(\%)$ & $n$ & $(\%)$ & & \\
\hline \multicolumn{5}{|c|}{ Death of family member } & $5.03(1.9-13.5)$ & $<0.00$ \\
\hline Yes & 104 & $(95.4)$ & 120 & $(80.5)$ & & \\
\hline No & 5 & $(4.6)$ & 29 & (19.5) & & \\
\hline Total & 109 & $(100)$ & 149 & $(100)$ & & \\
\hline \multicolumn{5}{|l|}{ CIDI Depression } & $3.8(1.9-7.7)$ & $<0.00$ \\
\hline Yes & 29 & $(26.6)$ & 13 & (8.7) & & \\
\hline No & 80 & (73.4) & 136 & $(91.3)$ & & \\
\hline Total & 109 & $(100)$ & 149 & $(100)$ & & \\
\hline \multicolumn{5}{|c|}{ Exposed to $\geq 16$ events } & $2.8(1.5-5.3)$ & $<0.00$ \\
\hline Yes & 30 & (27.5) & 18 & $(12.1)$ & & \\
\hline No & 79 & (72.5) & 131 & $(87.9)$ & & \\
\hline Total & 109 & $(100)$ & 149 & $(100)$ & & \\
\hline \multicolumn{5}{|c|}{ Stolen possession } & $2.0(1.2-3.4)$ & $<0.01$ \\
\hline Yes & 75 & $(69.4)$ & 79 & $(53.0)$ & & \\
\hline No & 33 & $(30.6)$ & 70 & $(47.0)$ & & \\
\hline Total & 108 & $(100)$ & 149 & $(100)$ & & \\
\hline \multicolumn{5}{|c|}{ Witness violence } & $2.9(1.2-6.8)$ & 0.02 \\
\hline Yes & 102 & (93.6) & 125 & (83.9) & & \\
\hline No & 7 & (6.4) & 24 & $(16.1)$ & & \\
\hline Total & 109 & $(100)$ & 149 & $(100)$ & & \\
\hline \multicolumn{5}{|l|}{ III health } & $2.4(1.1-4.9)$ & 0.02 \\
\hline Yes & 94 & (89.9) & 117 & $(79.1)$ & & \\
\hline No & 11 & $(10.1)$ & 31 & $(20.9)$ & & \\
\hline Total & 109 & $(100)$ & 148 & $(100)$ & & \\
\hline \multicolumn{5}{|l|}{ Witness death } & $2.0(1.1-3.3)$ & 0.02 \\
\hline Yes & 82 & (75.9) & 93 & $(62.4)$ & & \\
\hline No & 26 & $(24.1)$ & 56 & $(37.6)$ & & \\
\hline Total & 108 & $(100)$ & 149 & $(100)$ & & \\
\hline \multicolumn{5}{|c|}{ Shortage of clothing } & $1.7(1.0-2.8)$ & 0.04 \\
\hline Yes & 71 & $(65,7)$ & 79 & $(53.0)$ & & \\
\hline No & 37 & (34.3) & 70 & $(47.0)$ & & \\
\hline Total & 108 & $(100)$ & 149 & $(100)$ & & \\
\hline
\end{tabular}

${ }^{a} P T S D$, post traumatic stress disorder.

${ }^{b} \mathrm{OR}$, odds ratio.

${ }^{\mathrm{C}} \mathrm{Cl}$, confidence interval.

psycho-trauma we expected a lower prevalence of PTSD in the females but this was not the finding. There was no significant difference in the PTSD prevalence between the genders. This could suggest that women have a higher risk of developing PTSD due to lower threshold from exposure to psycho-trauma compared to men. This finding has been demonstrated in previous studies (16).

The prevalence of $42 \%$ for PTSD is high when compared with findings from similar studies among Guatemalan refugees with PTSD prevalence of $11.2 \%$ and prevalence of $5.6 \%$ among Bosnian refugees. The prevalence of PTSD among IDPs found in this study is similar to the $41 \%$ found by Obilom et al. in Northern Nigeria in different set of IDPs displaced by a different conflict but lower than the 54\% found among Ugandan IDPs in Northern Uganda.
Table 5 | Independent predictors of PTSD ${ }^{\mathrm{a}}$ among IDPs on multivariate analysis.

\begin{tabular}{lcccc}
\hline Term & $\begin{array}{c}\text { PTSD } \\
\text { AOR }\end{array}$ & & & \\
& 95\% $\mathbf{~ C l}^{\mathbf{b}}$ & $\boldsymbol{p}$ Value \\
\hline CIDI depression (yes/no) & 3.5271 & 1.6641 & 7.4757 & 0.001 \\
Death of family (yes/no) & 3.6679 & 1.1694 & 11.5049 & 0.0259 \\
III health (yes/no) & 1.677 & 0.7309 & 3.8478 & 0.2225 \\
$\begin{array}{l}\text { Shortage of clothing } \\
\text { (yes/no) }\end{array}$ & 1.1906 & 0.6646 & 2.1332 & 0.5575 \\
$\begin{array}{l}\text { Stolen possessions } \\
\text { (yes/no) }\end{array}$ & 1.5012 & 0.8289 & 2.7189 & 0.1801 \\
$\begin{array}{l}\text { Exposed to } \geq 16 \text { trauma } \\
\text { events (yes/no) }\end{array}$ & 1.7406 & 0.8129 & 3.7269 & 0.1537 \\
$\begin{array}{l}\text { Witness violence } \\
\text { (yes/no) }\end{array}$ & 1.9378 & 0.6921 & 5.4255 & 0.2079 \\
$\begin{array}{l}\text { Witnessed death } \\
\text { (yes/no) }\end{array}$ & 1.4134 & 0.7474 & 2.6727 & 0.2872 \\
\hline
\end{tabular}

a PTSD, post traumatic stress disorder.

${ }^{b} \mathrm{Cl}$, confidence interval.

Italic fonts represent data that were of statistical significance.

We found death of a family member and co-morbid depression to be the only independent predictors of PTSD among the IDPs. Several studies have found association between PTSD and depression $(19,20)$. Depressive disorders can occur independently after exposure to psycho-trauma and a previous depressive disorder is a risk factor for developing PTSD. We did not find significant association between socio-demographic characteristics and PTSD despite the high degree of unemployment among the IDPs. Despite the apparent poor social provisions at the camp, the IDPs did not report significant poor psychosocial adjustment, this may be explained by the lack of social amenities that is characteristic of communities were the IDPs were living prior to the conflict. The communities lack portable water, poor environmental sanitation, and poor housing conditions. Therefore, the camp condition may not differ significantly from their pre conflict environmental conditions and thus have little effects on IDPs psychosocial adjustment.

The findings of this study are subjected to the following limitations. This study was conducted 2 years post conflict therefore recall bias was possible but the nature of the psycho-trauma made it possible that the IDPs recollected their experience easily. The response to sensitive traumatic events, especially rape and molestation may have been under reported, especially among the females. We studied only IDPs living in the camps and excluded those that were staying with relatives or have moved out of the camps for other reasons. Some researchers have questioned the validity of PTSD diagnosis in non-western setting (21), but the instruments used for this study have been widely used and validated for different cultural settings. 


\section{CONCLUSION}

We concluded that exposure to psycho-trauma among IDPs living in Hajj camp in Kaduna, Northern Nigeria led to post conflict PTSD. Though males were more exposed to psycho-trauma there was no difference in gender PTSD prevalence. Death of a family member and co-morbid depression were independent predictors of PTSD among the IDPs. Though there living condition was poor, the IDPs had good psychosocial adjustment. PTSD among the IDPs can be predicted by IDPs who witnessed the death of a family member or had a co-morbid diagnosis of depression. We recommended a structured psychosocial intervention among the IDP targeted at improving living conditions and dealing with the consequences of psycho-trauma to the state government. We also advocated for the setting up of weekly mental health clinic in the camp to help those IDPs with mental distress.

\section{REFERENCES}

1. USIP. Nigeria's 2011 Elections: Best Run, but Most Violent [Internet]. United States Institute of Peace (2011). Available from: www.usip.org/files/resources/PB 103.pdf

2. The Nordic African Institute: Ethno-religious conflicts in Northern Nigeria [Internet]. (2012). Available from: www.nai.uu.se/publications/news/archives/ 042ibrahimkazah

3. Obilom R, Thacher T. Posttraumatic stress disorder following ethno-religious conflict in Jos, Nigeria. J Interpers Violence (2008) 23(8):1108-19. doi:10.1177/ 0886260507313975

4. Kish L. Survey Sampling. New York, NY: John Wiley and Sons (1965). p. 59-60.

5. Weine S, Becker D, McGlashan T, Laub D, Lazrove S, Vojvoda D. Clinical assessments and trauma testimonies of newly resettled Bosnian refugees. Am J Psychiatry (1995) 152:536-42.

6. Moti R, Dishman RK, Saunders RP, Dawda M, Pate RR. Measuring social provisions for physical activity among adolescent black and white girls. Educ Psychol Meas (2004) 64(4):682-706. doi:10.1177/0013164404263880

7. Pez O, Gilbert F, Bitfoi A, Carta MG, Jordanova V, Garcia-Mahia C, et al. Validity across translations of short survey psychiatric diagnostic instruments: CIDISF and CIS-R versus SCID-I/NP in four European countries. Soc Psychiatry Psychiatr Epidemiol (2010) 45(12):1149-1159. doi:10.1007/s00127-009-0158-6

8. Gureje O, Lasebikan VO, Kola L, Makanjuola VA. Lifetime and 12-month prevalence of mental disorders in the Nigerian survey of mental health and well-being. Br J Psychiatry (2006) 188:465-71. doi:10.1192/bjp.188.5.465

9. Mollica R, Caspi-Yavin Y, Bollini P, Truong T, Tor S, Lavelle J. The Harvard trauma questionnaire. Validating a cross-cultural instrument for measuring torture, trauma, and posttraumatic stress disorder in Indochinese refugees. J Nerv Ment Dis (1992) 180(2):111-6. doi:10.1097/00005053-199202000-00008

10. American Psychiatric Association. Cautionary statement. In: Diagnostic and Statistical Manual of Mental Disorders. 4th ed., text rev. Washington, DC: APA (2000). doi:10.1176/appi.books.9780890423349.11547

11. Choi Y, Mericle A, Harachi TW. Using Rasch analysis to test the crosscultural item equivalence of the Harvard trauma questionnaire and the Hopkins symptom checklist across Vietnamese and Cambodian immigrant mothers. $J$ Appl Meas (2006) 7(1):16-38.

12. Ichikawa M, Nakahara S, Wakai S. Cross-cultural use of the predetermined scale cutoff points in refugee mental health research. Soc Psychiatry Psychiatr Epidemiol (2006) 41(3):248-50. doi:10.1007/s00127-005-0016-2

13. Silove D, Manicavasagar V, Mollica R, Thai M, Khiek D, Lavelle J, et al. Screening for depression and PTSD in a Cambodian population unaffected by war: comparing the Hopkins symptom checklist and Harvard trauma questionnaire with the structured clinical interview. J Nerv Ment Dis (2007) 195(2):152-7. doi:10.1097/01.nmd.0000254747.03333.70

14. Fawzi MCS, Pham T, Lin L, Nguyen TV, Ngo D, Murphy E, et al. The validity of posttraumatic stress disorder among Vietnamese refugees. J Trauma Stress (1997) 10(1):101-8. doi:10.1023/A:1024812514796

15. Kleijn W, Hovens J, Rodenburg J. Posttraumatic stress symptoms in refugees assessments with the Harvard trauma questionnaire and the Hopkins symptom checklist-25 in different languages. Psychol Rep (2001) 88(2):527-32. doi:10.2466/pr0.2001.88.2.527

16. Roberts B, Ocaka K, Browne J, Oyok T, Sondorp E. Factors associated with posttraumatic stress disorder and depression amongst internally displaced persons in northern Uganda. BMC Psychiatry (2008) 8:38. doi:10.1186/1471-244X-8-38

17. Mollica R, Massagli L, Silove D. Measuring Trauma, Measuring Torture. Cambridge, MA: Harvard University (2004).

18. Oruc L, Kapetanovic A, Pojskic N, Miley K, Forstbauer S, Mollica RF, et al. Screening for PTSD and depression in Bosnia and Herzegovina: validating the Harvard trauma questionnaire and the Hopkins symptom checklist. Int J Cult Ment Health (2008) 1(2):105-16. doi:10.1080/17542860802456620

19. Grant NM, Terry LS, Marc NE, Megan SB, Chi-Ah C. Mental health of Cambodian refugees 2 decades after resettlement in the United States. JAMA (2005) 294(5):571-9. doi:10.1001/jama.294.5.571

20. Mollica R, McInnes K, Poole C, Pham T, Smith Fawzi M, Murphy ELL. The dose-effect relationships between torture and psychiatric symptoms in Vietnamese ex-political detainees and a comparison group. J Nerv Ment Dis (1998) 186:543-53. doi:10.1097/00005053-199809000-00005

21. Summerfield D. The invention of post-traumatic stress disorder and the social usefulness of a psychiatric category. BMJ (2001) 322(7278):95-8. doi:10.1136/ bmj.322.7278.95

Conflict of Interest Statement: The authors declare that the research was conducted in the absence of any commercial or financial relationships that could be construed as a potential conflict of interest.

Received: 25 June 2014; accepted: 28 August 2014; published online: 12 September 2014. Citation: Sheikh TL, Mohammed A, Agunbiade S, Ike J, Ebiti WN and Adekeye $O$ (2014) Psycho-trauma, psychosocial adjustment, and symptomatic post-traumatic stress disorder among internally displaced persons in Kaduna, Northwestern Nigeria. Front. Psychiatry 5:127. doi: 10.3389/fpsyt.2014.00127

This article was submitted to Affective Disorders and Psychosomatic Research, a section of the journal Frontiers in Psychiatry.

Copyright (c) 2014 Sheikh, Mohammed, Agunbiade, Ike, Ebiti and Adekeye. This is an open-access article distributed under the terms of the Creative Commons Attribution License (CC BY). The use, distribution or reproduction in other forums is permitted, provided the original author(s) or licensor are credited and that the original publication in this journal is cited, in accordance with accepted academic practice. No use, distribution or reproduction is permitted which does not comply with these terms. 